\title{
Carbon Dioxide-Driven Coupling in a Two-Compartment System: Methyl Red Oscillator
}

\author{
Norbert Német, Gábor Holló, and István Lagzi*
}

Cite This: J. Phys. Chem. A 2020, 124, 10758-10764

Read Online

ABSTRACT: Strategies for designing autonomous oscillatory systems have gained much attention in the past few decades. A broadly accepted and used strategy for the generation of forced oscillations in the originally non-oscillatory subsystems is to couple a $\mathrm{pH}$ (driving) oscillator to a $\mathrm{pH}$-sensitive substance (forced oscillatory subsystem) in a one-compartment system. The forced oscillatory subsystem comprises $\mathrm{pH}$-sensitive components, which inevitably generate negative feedback and affect the characteristics of the driving oscillatory system. Here, we present a different approach by separating

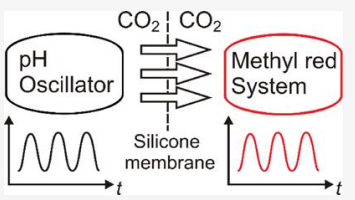
the driving and forced oscillatory systems into a two-compartment system using a silicone membrane, and the forced oscillations of the absorbance of a $\mathrm{pH}$-sensitive chemical species (methyl red dye) were realized by the transport of carbon dioxide through the membrane generated periodically by the driving $\mathrm{pH}$ oscillator. The transported carbon dioxide produced the $\mathrm{pH}$ change in the separated compartment by carbon dioxide-hydrogen carbonate-carbonate equilibria and created forced oscillations of a $\mathrm{pH}$ sensitive chemical species manifested in the oscillation of its absorbance at a fixed wavelength. This approach avoids any feedback from the forced oscillatory system to the driving system via the cross-membrane transport of the chemical species from the forced to the driving oscillatory system. Additionally, we present that this carbon dioxide coupling to the methyl red dye can be used to estimate the carbon dioxide content in both liquid and gas phases.

\section{INTRODUCTION}

Designing and introducing new strategies for the regulation and controlling of $\mathrm{pH}$-sensitive subsystems using autonomous $\mathrm{pH}$ oscillators are fundamentally important and challenging not only from the basic science point of view, but these investigations have provided more insight into how these oscillators can be used in diversified applications (e.g., $\mathrm{pH}$ driven drug release, molecular machine, and membrane permeability). ${ }^{1-7} \mathrm{pH}$ oscillators are a class of chemical oscillators in which the concentration of $\mathrm{H}^{+}$ions $(\mathrm{pH})$ oscillates autonomously, induced by coupling of an autocatalytic cycle to a negative feedback loop. ${ }^{8,9}$ These $\mathrm{pH}$ oscillations have been sustained in open systems realized by using continuously stirred tank reactors (CSTRs). ${ }^{10,11}$

A common strategy for the generation of forced oscillations in the originally non-oscillatory subsystems is to design a onecompartment system incorporating the driving $\mathrm{pH}$ oscillator and the $\mathrm{pH}$-sensitive system comprising ions, ${ }^{12-15}$ molecules, $^{16-19}$ nanoscopic building blocks, ${ }^{2-23}$ or polymers (gels). ${ }^{24-26}$ The periodically changed $\mathrm{pH}$, driven by the oscillator, shifts the equilibria of the $\mathrm{pH}$-sensitive chemical entities, thus changing the ratio of the concentrations of the protonated and deprotonated forms manifesting in the change of the chemical/physical properties of the system. Sometimes, these forced concentration oscillations can be easily observed via complexation, precipitation, or aggregation. ${ }^{12}$ Based on this strategy, several oscillatory systems have been designed and introduced such as oscillatory systems of non-redox mono-, di-, and trivalent cations, ${ }^{13-15}$ DNAs, ${ }^{16,17}$ nanoparticles, ${ }^{20-22}$ vesicles, $^{27}$ and $\mathrm{pH}$-responsive gels. ${ }^{24}$
It is an important question in these studies on how the forced subsystems can affect and in which extend the behavior of the driving $\mathrm{pH}$ oscillatory system since these subsystems are $\mathrm{pH}$-sensitive; thus, they can consume or generate $\mathrm{H}^{+}$ions affecting the characteristics of the driving $\mathrm{pH}$ oscillators (time period and the amplitude of the $\mathrm{pH}$ oscillation). It has been shown that, in a one-compartment system, if the concentrations of the forced oscillatory species are high enough, then the subsystem might damp the $\mathrm{pH}$ oscillations or even suppress them. ${ }^{28}$

In this study, we propose a novel coupling strategy to drive the oscillation of an originally non-oscillatory chemical species, namely, a pH-sensitive dye (methyl red, MR) in a twocompartment system by separating the $\mathrm{pH}$ oscillator and the solution of the $\mathrm{pH}$-sensitive chemical species using a silicone membrane. A similar strategy was used to control the regular and chaotic oscillation regimes in the sulfite-hydrogen peroxide $\mathrm{pH}$ oscillatory system. ${ }^{29}$ The forced oscillations were realized by the selective transport of carbon dioxidegenerated periodically in the $\mathrm{pH}$ oscillator-from the $\mathrm{pH}$ oscillator to the solution of the dye that changed periodically the $\mathrm{pH}$ in the non-oscillatory subsystem (solution of MR). The

Received: October 25, 2020

Revised: December 2, 2020

Published: December 15, 2020 
periodic change in the transport of carbon dioxide through the silicone membrane affected the $\mathrm{pH}$ of the MR solution through carbon dioxide-hydrogen carbonate-carbonate equilibria. This generated $\mathrm{pH}$ change affected the ratio of the protonated/deprotonated forms of the MR molecules, which involved the oscillations of the absorbance (color) of MR at a given wavelength. The MR dye was chosen because it has $\mathrm{pKa}$ $=4.95$ in the range of the $\mathrm{pH}$ that can be generated and maintained by carbon dioxide-hydrogen carbonate-carbonate equilibria. $^{30}$

\section{EXPERIMENTAL AND NUMERICAL METHODS}

2.1. Experimental Methods. The bromate-sulfite $\mathrm{pH}$ oscillator was used as a driving system in a CSTR for the periodic generation of carbon dioxide, ${ }^{31-37}$ and the water solution of MR was flowed through in a Tygon-silicone tube system (Tygon tube with an overall length of $200 \mathrm{~cm}$ and a diameter of $0.6 \mathrm{~mm}$ and a silicone tube with a length and diameter of $100 \mathrm{~cm}$ and $0.4 \mathrm{~mm}$, respectively). Tygon and silicon tubes were connected with small pieces of Teflon tubes. A flow-through quartz cuvette $(V=1.0 \mathrm{~mL})$ was placed in a spectrophotometer (VWR UV-1600PC spectrophotometer), and it was connected to the Tygon-silicone tube system to investigate the absorbance change in the MR solution caused by the transport of carbon dioxide through the silicone tube, which was immersed in the $\mathrm{pH}$ oscillator (Figure 1a).

In the experiments, we used the following reagent-grade chemicals: $\mathrm{NaBrO}_{3}$ (Sigma-Aldrich), $\mathrm{Na}_{2} \mathrm{SO}_{3}$ (Sigma-Aldrich), $\mathrm{H}_{2} \mathrm{SO}_{4}$ (Sigma-Aldrich), $\mathrm{NaHCO}_{3}$ (Fluka), and MR solution (60 v/v\% ethanol; 40 v/v\% water, Sigma-Aldrich). The aqueous stock solutions of all chemicals were prepared freshly before the experiment to avoid any decay of chemicals and the oxidation of sulfite. In a typical experiment, the $\mathrm{pH}$ oscillation was sustained in a CSTR with a volume of $22.0 \mathrm{~mL}$ at $45.5 \pm$ $0.5^{\circ} \mathrm{C}$. The CSTR was continuously fed by two channels using a peristaltic pump (Ismatec) with a constant flow rate $(Q=$ $0.286 \mathrm{~mL} / \mathrm{min}$ ) of the two stock solutions: (i) a solution of acid and bromate $\left(100 \mathrm{~mL}\left[\mathrm{H}_{2} \mathrm{SO}_{4}\right]_{0}=6.4 \mathrm{mM}\right.$ and $\left[\mathrm{BrO}_{3}^{-}\right]_{0}=$ $0.2 \mathrm{M})$ and (ii) a solution of sulfite and bicarbonate $(100 \mathrm{~mL}$ $\left[\mathrm{SO}_{3}^{2-}\right]_{0}=158.4 \mathrm{mM}$ and $\left.\left[\mathrm{HCO}_{3}^{-}\right]_{0}=4.0 \mathrm{mM}\right)$. Another peristaltic pump (Ismatec) was used to keep a constant volume of the reaction mixture in the CSTR. The reaction mixture was stirred with a magnetic stirrer (DragonLab MS-PA) at 530 rpm. The $\mathrm{pH}$ in the CSTR was measured by a $\mathrm{pH}$ microelectrode (Mettler Toledo).

The stock solution of MR was diluted with distilled water to obtain a concentration of $0.03 \mathrm{mM}\left([\mathrm{MR}]_{0}=0.03 \mathrm{mM}\right)$, and its $\mathrm{pH}$ was adjusted to $\mathrm{pH}=7.04$ with a sodium hydroxide solution (Sigma-Aldrich). Prior to the experiments, the tube system was saturated with the MR molecules (MR solution with a concentration of $0.03 \mathrm{mM}$ and a flow rate of $0.82 \mathrm{~mL} /$ min was flowing through the tube system for $t=2 \mathrm{~h}$ ). In the experiments, the solution of MR was continuously flowed through the tube-cuvette system with a constant flow rate $(Q=$ $0.82 \mathrm{~mL} / \mathrm{min})$. Further experiments were carried out with buffered $\mathrm{MR}$ solutions having $\mathrm{pH}$ of 6.71 and 5.50 using $\mathrm{Na}_{2} \mathrm{HPO}_{4}$ heptahydrate (Sigma-Aldrich) and $\mathrm{NaH}_{2} \mathrm{PO}_{4}$ dihydrate (Sigma-Aldrich).

The silicone tube used in the experiments was highly permeable for gas-phase components such as carbon dioxide; hydrated ions could not cross the membrane. In our approach, the coupling species was carbon dioxide, which is part of the bromate-sulfite oscillator and MR subsystem as well. The a)

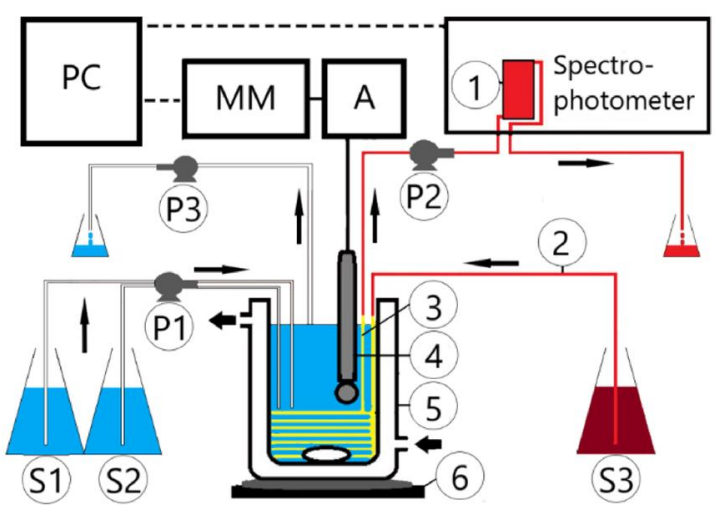

b)

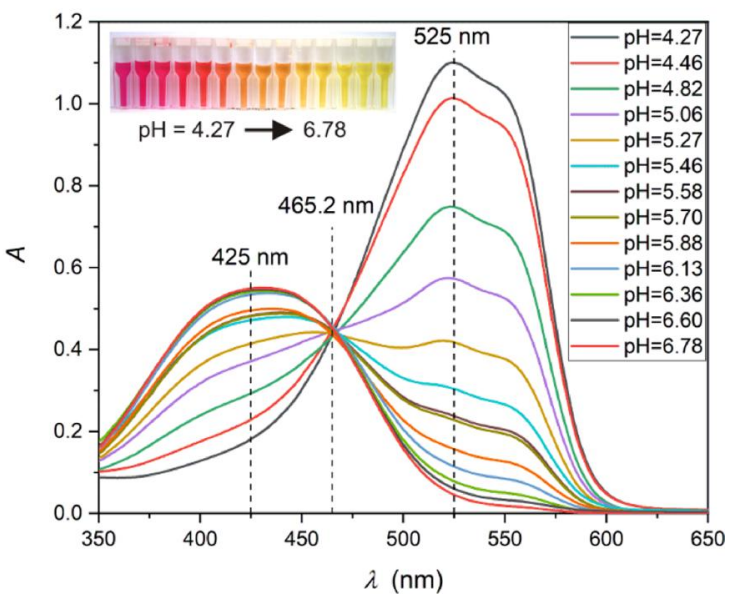

Figure 1. (a) Scheme of the unidirectional coupling of the bromatesulfite $\mathrm{pH}$ oscillator to the forced methyl red oscillator. The bromatesulfite $\mathrm{pH}$ oscillator and the solution of methyl red dye are separated by a silicone membrane, which is penetrable for the periodically produced gas-phase carbon dioxide. 1: quartz (flow-through) cuvette; 2: Tygon tube (red); 3: silicone tube (yellow); 4: $\mathrm{pH}$ electrode; 5: thermostated CSTR; 6: magnetic stirrer; MM: multimeter; A: amplifier; PC: computer. S1: bromate-acid solution; S2: sulfitebicarbonate solution; S3: MR solution. P1, P2, and P3 are peristaltic pumps (with different flow rates). (b) UV-vis spectra and colors of the MR solutions at various $\mathrm{pH}$ values.

absorbance (color) change of MR solution was monitored at 425 (basic peak) and $465 \mathrm{~nm}$ (isosbestic point) wavelengths (Figure 1b).

2.2. Numerical Model. A two-compartment numerical model was developed to investigate the carbon dioxide coupling, the forced $\mathrm{pH}$ oscillation in the MR solution, and the subsequent absorbance oscillation of the dye. The system consists of two compartments: (i) bromate-sulfite $\mathrm{pH}$ oscillator and (ii) solution of MR in the silicone tube, which is coupled to the $\mathrm{pH}$ oscillatory system via the transport of carbon dioxide through the silicone membrane. The forced subsystem was considered as a CSTR in the simulation. Therefore, the concentration changes of the chemical species in time can be similarly described by the set of ordinary differential equations (ODEs) in the CSTR and silicone tube

$$
\frac{d c_{i}^{\mathrm{osc}}}{d t}=R_{i}^{\mathrm{osc}}+\kappa_{i}^{\mathrm{osc}}\left(c_{0 i}^{\mathrm{osc}}-c_{i}^{\mathrm{osc}}\right)
$$


a)

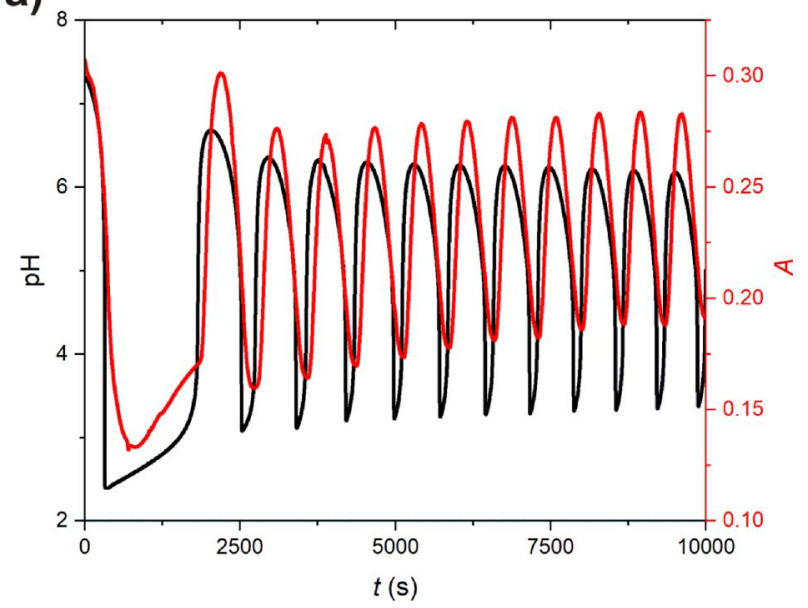

b)

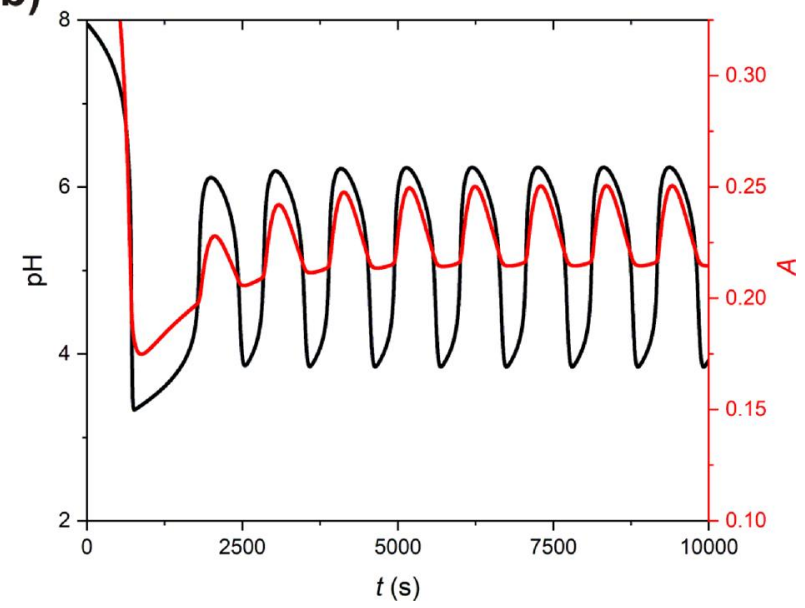

Figure 2. $\mathrm{pH}$ oscillations of the driving bromate-sulfite system and the forced oscillation of the absorbance of the MR solution $(c=0.03 \mathrm{mM})$ adjusted to $\mathrm{pH}=7.04$ at $\lambda=425 \mathrm{~nm}$ in the experiments (a) and numerical simulations (b). The flow rate of the MR solution in the tube was $Q=$ $0.84 \mathrm{~mL} / \mathrm{min}$.

$$
\frac{d c_{i}^{\text {tube }}}{d t}=R_{i}^{\text {tube }}+\kappa_{i}^{\text {tube }}\left(c_{0 i}^{\text {tube }}-c_{i}^{\text {tube }}\right)
$$

where $c_{i}, c_{0 i}, R_{i}$, and $\kappa_{i}$ are the concentrations of the $i$ th chemical species in the CSTR ( $\mathrm{pH}$ oscillator) and MR solution (silicone tube), the concentration of $i$ th chemical species in the input feed, $R_{i}$ is the reaction rate, and $\kappa_{i}$ is the reciprocal of the residence time. The coupling between two systems (eqs 1 and 2 ) is realized by carbon dioxide transfer through the silicone membrane, which can be described by the following equations

$$
\begin{gathered}
\frac{d c_{\mathrm{CO}_{2}(\mathrm{aq})}^{\mathrm{tube}}}{d t}=-n k_{t}\left(c_{\mathrm{CO}_{2}(\mathrm{aq})}^{\mathrm{tube}}-c_{\mathrm{CO}_{2}(\mathrm{aq})}^{\text {osc }}\right) \\
\frac{d c_{\mathrm{CO}_{2}(\mathrm{aq})}^{\text {osc }}}{d t}=k_{t}\left(c_{\mathrm{CO}_{2}(\mathrm{aq})}^{\text {tube }}-c_{\mathrm{CO}_{2}(\mathrm{aq})}^{\text {osc }}\right)
\end{gathered}
$$

where $k_{t}$ is the transfer rate constant for carbon dioxide from the $\mathrm{pH}$ oscillator to the MR solution and $n$ is the ratio of the volumes of the $\mathrm{pH}$ oscillator and $\mathrm{MR}$ solution in the silicone tube. The sets of the ODEs were solved numerically by using MATLAB with an ode15s solver (absolute tolerance: $10^{-14}$ and relative tolerance: $\left.10^{-10}\right)$. The chemical mechanisms and parameters used in the simulations can be found in the Supporting Information (Tables S1-S5). The absorbance of MR was obtained from the calculated concentration and molar absorbance coefficient estimated from the experimental data (Figure S1, Supporting Information).

\section{RESULTS AND DISCUSSION}

The basic concept of our strategy is that the coupling chemical species (in our case, it is carbon dioxide) is involved in both systems, namely, in the bromate-sulfite $\mathrm{pH}$ oscillator and MR solution separated by a silicone membrane (tube). The amount of $\mathrm{CO}_{2}$ in the $\mathrm{pH}$ oscillator is determined by the $\mathrm{pH}$ through carbon dioxide-hydrogen carbonate-carbonate equilibria; at lower $(\mathrm{pH} \sim 3)$ and higher $(\mathrm{pH} \sim 6) \mathrm{pH}$, more and less $\mathrm{CO}_{2}$ is present, respectively. The silicone membrane is selectively permeable for the gas-phase carbon dioxide, and the flux rate through the membrane is proportional to the concentration of $\mathrm{CO}_{2}$ in the $\mathrm{pH}$ oscillatory system. Carbon dioxide that entered to the MR solution affects and changes the actual $\mathrm{pH}$ in the tube again through carbon dioxide-hydrogen carbonatecarbonate equilibria, which affects the ratio of the protonated and deprotonated MR molecules in the solution, thus involving the change of its absorbance at a given wavelength (or in other words, the color of the dye solution). Since the amount of the $\mathrm{CO}_{2}$ changes periodically in the driving oscillatory system, the concentration of the $\mathrm{CO}_{2}$ changes periodically almost in-phase as well as in the MR solution. Figure 2 shows the results of this coupling strategy in the experiments (Figure 2a) and numerical simulations (Figure $2 \mathrm{~b}$ ). It can be seen that the $\mathrm{pH}$ oscillator generated in-phase oscillation of the absorbance of the MR solution at $\lambda=425 \mathrm{~nm}$. Furthermore, a slight time delay $(\sim 127$ s) can be observed between the peaks of the $\mathrm{pH}$ oscillator and forced subsystem, which is attributed to the fact that the solution in the silicone tube region (where the $\mathrm{CO}_{2}$ exchange takes place) should be transported into the flow cuvette (placed in the spectrophotometer). Based on the overall volume of the tubes (between the silicone tube and cuvette) and the flow rate of the forced subsystem, the transport time is $\sim 120 \mathrm{~s}$, which is in good accordance with the time delay between the peaks of the oscillations. In the simulations, such a transport time was not included; therefore, there is no phase difference between the oscillations of the $\mathrm{pH}$ oscillatory and MR systems.

When the $\mathrm{pH}$ is low in the bromate-sulfite oscillatory system, more dissolved $\mathrm{CO}_{2}$ is generated. This increased amount of carbon dioxide penetrates into the $\mathrm{MR}$ solution through the silicone membrane, decreasing the $\mathrm{pH}$ there. The experiments were carried out at the basic peak of the MR spectrum $(\lambda=425 \mathrm{~nm}$; Figure $1 \mathrm{~b})$ in which smaller $\mathrm{pH}$ results in smaller absorbance. Therefore, the absorbance decreases when more $\mathrm{CO}_{2}$ is produced in the $\mathrm{pH}$ oscillator, generating smaller $\mathrm{pH}$ (more acidic environment) in the MR solution. Similarly, when the $\mathrm{pH}$ is high in the $\mathrm{pH}$ oscillatory system, less dissolved $\mathrm{CO}_{2}$ is generated, causing less decrease of the $\mathrm{pH}$ in the MR solution compared to the case when the $\mathrm{pH}$ is low in the driving system. Higher $\mathrm{pH}$ results in greater absorbance of the solution of MR. Based on these effects, an in-phase oscillation in the $\mathrm{pH}$ of the oscillator and absorbance of the MR solution can be observed (Figure 2). The $\mathrm{pH}$ of the effluent MR solution from the flow cuvette was measured as 
well, the recorded $\mathrm{pH}$ change $(\Delta \mathrm{pH})$ was around 0.5 , and the $\mathrm{pH}$ in the MR solution oscillated between 6.27 and 6.75 .

A control experiment was carried out in which a buffered solution of $\mathrm{MR}$ was used and fixed at $\mathrm{pH}=6.71 \mathrm{using}$ phosphate mono- $(0.212 \mathrm{M})$ and dibasic $(0.288 \mathrm{M})$ sodium salts. The aim of this investigation was two-fold; first, we wanted to confirm that the forced oscillation of absorbance is attributed to the transport of $\mathrm{CO}_{2}$ from the $\mathrm{pH}$ oscillator to the $\mathrm{MR}$ solution and its effect on the $\mathrm{pH}$. Second, we wanted to exclude the effect of the bromination of MR molecules. Figure 3 presents the results of this control experiment, and it can be

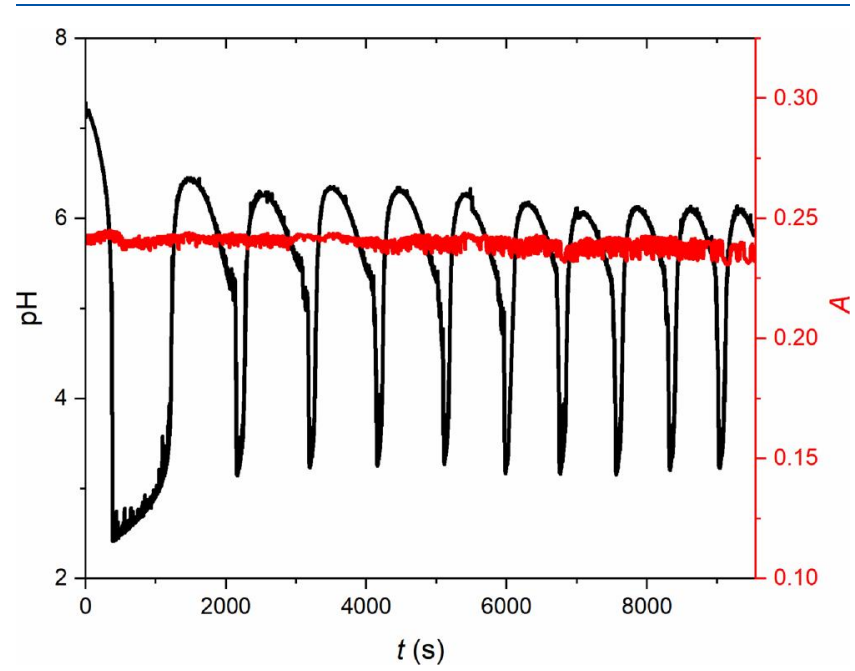

Figure 3. $\mathrm{pH}$ oscillations of the driving bromate-sulfite system and absorbance of the MR solution $(c=0.03 \mathrm{mM})$ buffered by phosphate salts to $\mathrm{pH}=6.71$ at $\lambda=425 \mathrm{~nm}$ in the experiments. The flow rate of the MR solution in the tube was $Q=0.84 \mathrm{~mL} / \mathrm{min}$.

observed that there is no oscillation of the absorbance at $\lambda=$ $425 \mathrm{~nm}$, even when the $\mathrm{pH}$ oscillation occurred in the $\mathrm{pH}$ oscillatory system. This means that there was a transport of carbon dioxide; however, due to the buffered medium, it could not change the $\mathrm{pH}$ in the MR solution.

It should be noted that the increased flux of carbon dioxide from the $\mathrm{pH}$ oscillator to the forced system through the silicone membrane can slightly affect the characteristics of the driving system. We carried out a control experiment in which an alkaline solution (sodium hydroxide, $0.2 \mathrm{M}$ ) was used in flow and no-flow conditions in the Tygon-silicone tube system. In the case of the flow of the alkaline solution, the concentration gradient of carbon dioxide (and its flux) between the $\mathrm{pH}$ oscillator and the solution in the tube can be maximized because all carbon dioxide turns to carbonate in the alkaline solution. When the flow of the alkaline solution was realized, the time period and the amplitude of the $\mathrm{pH}$ oscillations increased by $\sim 20$ and $\sim 30 \%$, respectively.

The bromination of MR is a well-known organic reaction under very acidic conditions in which the product of the reaction (brominated MR) is colorless, i.e., the absorbance of the MR solution gradually decreases in the course of the reaction. In addition to this, it is also evident that the $\mathrm{pH}$ oscillator generates periodically some bromine, more bromine at more acidic $\mathrm{pH}$, and less bromine at higher $\mathrm{pH}\left(\mathrm{BrO}_{3}{ }^{-}+\right.$ $\left.5 \mathrm{Br}^{-}+6 \mathrm{H}^{+} \rightarrow 3 \mathrm{Br}_{2}+3 \mathrm{H}_{2} \mathrm{O}\right)$ since bromate is an initial reagent and bromide is an intermediate product of the chemical system. Bromine, similarly to carbon dioxide, could penetrate through the silicone membrane. However, in the buffered medium of $\mathrm{MR}$, we could not observe any change in the absorbance (i.e., degradation of $\mathrm{MR}$ molecules), confirming that the bromination of MR can be neglected. We also carried out experiments in a buffer at lower $\mathrm{pH}(\mathrm{pH}=$ 5.55) using phosphate mono- $(0.184 \mathrm{M})$ and dibasic (0.015 $\mathrm{M})$ sodium salts. Similarly to the previous experiment at $\mathrm{pH}=$ 6.71 (Figure 3), we could record no change in the absorbance. This indicates that there is no bromination reaction in the MR solution at a $\mathrm{pH}$ range established by carbon dioxidehydrogen carbonate-carbonate equilibria. This finding supports the fact that the bromination of MR takes place only in very acidic conditions (in a sulfuric acid of $\sim 1 \mathrm{M}$ ). Therefore, the oscillation of the absorbance is solely caused by penetrated carbon dioxide.

Due to the unique property of the UV-vis spectra of watersoluble dyes, namely, the existence of the isosbestic point, no absorbance oscillation should occur at this wavelength $\left(\lambda_{i}=\right.$ $465 \mathrm{~nm}$ ) since the absorbance is $\mathrm{pH}$-independent at the isosbestic point. However, smaller amplitude oscillations were
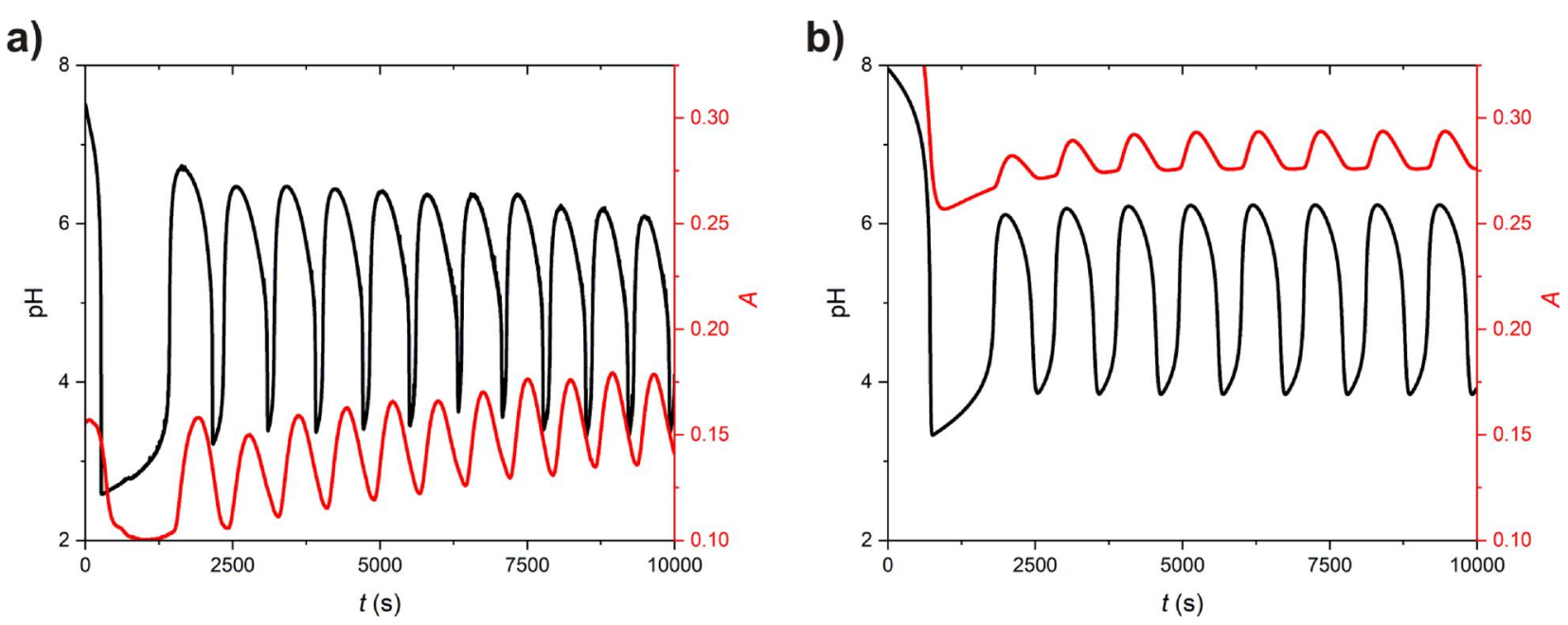

Figure 4. $\mathrm{pH}$ oscillations of the driving bromate-sulfite system and the forced oscillation of the absorbance of the MR solution $(c=0.03 \mathrm{mM})$ adjusted to $\mathrm{pH}=7.04$ at the isosbestic point $\left(\lambda_{i}=465 \mathrm{~nm}\right)$ in the experiments $(\mathrm{a})$ and numerical simulations $(\mathrm{b})$. The flow rate of the MR solution in the tube was $Q=0.84 \mathrm{~mL} / \mathrm{s}$. 
a)

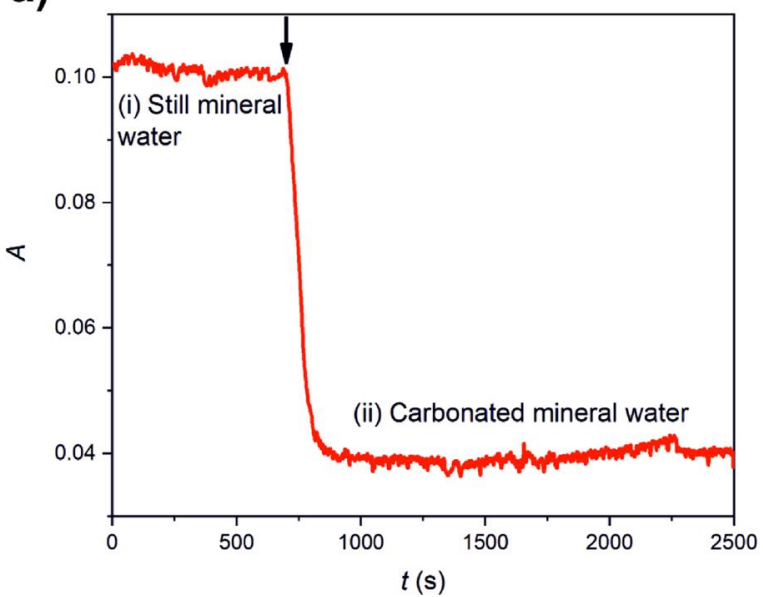

b)

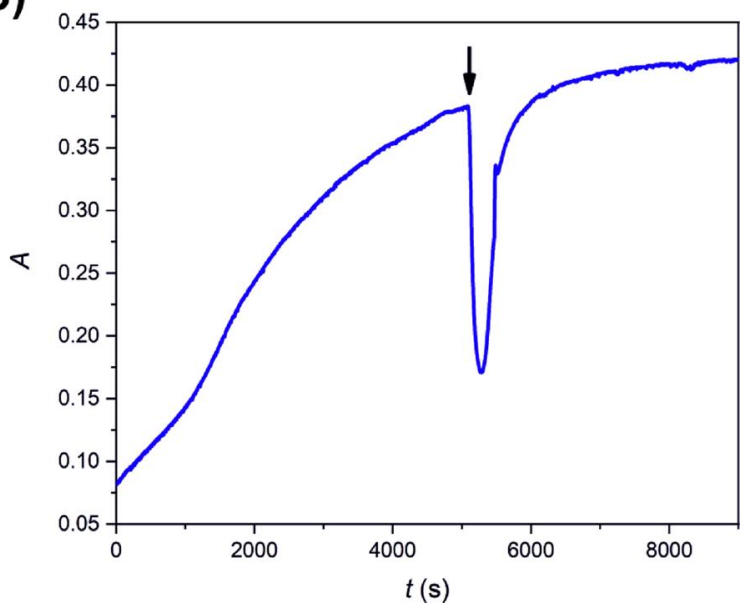

Figure 5. Application of the silicone membrane and the solution of $\mathrm{MR}$ as a $\mathrm{CO}_{2}$ sensor. Changing the absorbance of the MR solution in the silicone tube with a concentration of $0.03 \mathrm{mM}$ (the $\mathrm{pH}$ was adjusted to 7.04) at $\lambda=425 \mathrm{~nm}$ when the silicone tube (length and inner diameter of $1.0 \mathrm{~m}$ and $0.37 \mathrm{~mm}$, respectively) (a) was immersed into two types of commercially available mineral water: (i) still and (ii) carbonated; panel (b) was subjected to an expiration of $3 \mathrm{~min}$ to the silicone tube in air. The flow rate of the MR solution in the tube was $Q=0.36 \mathrm{~mL} / \mathrm{s}$.

observed at $\lambda_{i}=465 \mathrm{~nm}$ (Figure 4) as well. This unexpected behavior is because protonated MR molecules have a higher ability to be dissolved in the silicone membrane than the deprotonated (charged) ones. Figure S2 (Supporting Information) presents the color of the silicone and Tygon tubes used in the experiments, which supports our hypothesis that $\mathrm{MR}$ dissolves in the silicone tube, and it has a $\mathrm{pH}$-dependent penetration rate into the silicone tube due to its $\mathrm{pH}$-dependent charge states. This behavior was implemented in the numerical model to reproduce oscillations of the absorbance at the isosbestic point. MR molecules have two different chemical structures depending on the $\mathrm{pH}$, a quinonoid structure (neutral) in the acid medium and a benzenoid structure (charged) in the neutral and alkaline media (Figure S3, Supporting Information). When the $\mathrm{pH}$ was low in the CSTR (in the driving $\mathrm{pH}$ oscillator), more $\mathrm{CO}_{2}$ went through the silicone membrane into the MR solution, decreasing the $\mathrm{pH}$. In this more acidic environment, the MR molecules have no charge and higher ability to penetrate into the apolar silicone matrix (having a dielectric constant of 2-3), thus decreasing the MR concentration of the forced subsystem (causing a decrease in the absorbance). When the $\mathrm{pH}$ was greater in the CSTR, less $\mathrm{CO}_{2}$ was produced and transported into the MR solution, causing an increase of the $\mathrm{pH}$, which resulted in the formation of more charged MR molecules having less ability to penetrate into the silicone tube, which resulted in a higher concentration of MR in the solution. Since higher $\mathrm{pH}$ results in a higher concentration of $\mathrm{MR}$ in the solution and since the absorbance is proportional to the MR concentration, in-phase oscillations can be observed at the isosbestic point as well. In conclusion, based on the $\mathrm{pH}$-dependent penetration of MR into the silicone tube, it is possible to describe and understand the absorbance oscillations at the isosbestic point.

It should be noted that, away from the isosbestic point, a synergistic effect is present in the absorbance oscillation because the absorbance of the MR solution is affected by both the penetration ability of $\mathrm{MR}$ into the silicone and $\mathrm{pH}$ dependent absorbance of MR. At a lower $\mathrm{pH}$ state in the MR solution that generates higher dissolution ability (higher removal rate of MR from the solution) and a decrease of the absorbance of the MR molecules, both effects contribute to the decrease of the absorbance of MR. At a higher $\mathrm{pH}$ state, both effects have opposite trends generating less decrease of the absorbance compared to the lower $\mathrm{pH}$ state.

The change of the absorbance in the MR solution caused by the $\mathrm{CO}_{2}$ transport can be used as a working principle for a $\mathrm{CO}_{2}$ sensor since the absorbance change is proportional to the transported $\mathrm{CO}_{2}$, which is proportional to the amount of $\mathrm{CO}_{2}$ accumulated on another side of the silicone membrane. To illustrate the capability of the concept, we measured the relative content of $\mathrm{CO}_{2}$ in mineral waters and exhaled air. Figure 5 shows the results of the measurements of the $\mathrm{CO}_{2}$ content in mineral waters and expiration air. First, the silicone tube was immersed (with a flow of the MR solution in it) into still mineral water, and the absorbance showed a stationary value; once the silicone tube was placed into carbonated mineral water, the absorbance of the MR solution decreased and reached a new stationary value corresponding to an increased amount of carbon dioxide (Figure 5a). Similarly to this idea, we put the silicone tube in the air and exposed it to exhaled air, and after some time, the absorbance started to decrease (Figure 5b). Usually, there is a 100 -fold increase of $\mathrm{CO}_{2}$ over the inhaled amount. In our procedure, this was translated into the change of the absorbance of 0.21 units. Of course, to use this method in a quantitative assessment, calibration is needed before the measurements. We are fully aware that there are other most powerful methods to measure the $\mathrm{CO}_{2}$ content; however, we believe that it can be used in systems in which other methods face limitations (e.g., measurements in small volumes).

\section{CONCLUSIONS}

Here, we presented a novel approach to generate and drive the oscillation of a non-oscillatory chemical species utilizing a carbon dioxide transport through a silicone membrane from the driving $\mathrm{pH}$ oscillatory system to the forced oscillating system. Carbon dioxide changed the $\mathrm{pH}$ in the MR system, and since carbon dioxide generated periodically in the driving $\mathrm{pH}$ oscillatory system, the $\mathrm{pH}$ of the MR system changed as well via carbon dioxide-hydrogen carbonate-carbonate equilibria. Our reported technique can be used in other chemical systems to drive oscillation in a unidirectional way to 
eliminate any feedback effects that originated from the driving chemical system in the way of free radicals or oxidative conditions. For instance, this strategy could be applied to drive and control autonomously the activity of enzymatic reactions since their activities are $\mathrm{pH}$-dependent, and based on this approach, the enzymatic activity would oscillate in time. The main advantage of this approach is that the silicone membrane reduces the feedback from the driving oscillator to the originally non-oscillatory system.

\section{ASSOCIATED CONTENT}

\section{sI Supporting Information}

The Supporting Information is available free of charge at https://pubs.acs.org/doi/10.1021/acs.jpca.0c09632.

Kinetic model and its parameters used in the simulations (Tables S1-S5), dependence of the molar absorption coefficient, Tygon and silicone tubes used in the experiments, and molecular structures of the protonated and deprotonated forms of the methyl red molecule (Figures S1-S3) (PDF)

\section{AUTHOR INFORMATION}

\section{Corresponding Author}

István Lagzi - Department of Physics and MTA-BME Condensed Matter Physics Research Group, Budapest University of Technology and Economics, H-1111 Budapest, Hungary; ○ orcid.org/0000-0002-2303-5965; Phone: +361-463-1341; Email: istvanlagzi@gmail.com; Fax: $+361-463-4180$

\section{Authors \\ Norbert Német - Department of Physics, Budapest University of Technology and Economics, H-1111 Budapest, Hungary \\ Gábor Holló - MTA-BME Condensed Matter Physics Research Group, Budapest University of Technology and Economics, H-1111 Budapest, Hungary}

Complete contact information is available at: https://pubs.acs.org/10.1021/acs.jpca.0c09632

\section{Notes}

The authors declare no competing financial interest.

\section{ACKNOWLEDGMENTS}

Authors acknowledge the financial support of the National Research, Development and Innovation Office of Hungary (NN125752 and K131425) and the NRDI Fund (TKP2020 IES, grant no. BME-IE-NAT) based on the charter of bolster issued by the NRDI office under the auspices of the Ministry for Innovation and Technology.

\section{REFERENCES}

(1) Giannos, S. A.; Dinh, S. M.; Berner, B. Temporally Controlled Drug Delivery Systems: Coupling of $\mathrm{pH}$ Oscillators with Membrane Diffusion. J. Pharm. Sci. 1995, 84, 539-543.

(2) Misra, G. P.; Siegel, R. A. Multipulse Drug Permeation across a Membrane Driven by a Chemical $\mathrm{pH}$-Oscillator. J. Controlled Release 2002, 79, 293-297.

(3) Buyukcakir, O.; Yasar, F. T.; Bozdemir, O. A.; Icli, B.; Akkaya, E. U. Autonomous Shuttling Driven by an Oscillating Reaction: Proof of Principle in a Cucurbit[7]Uril-Bodipy Pseudorotaxane. Org. Lett. 2013, 15, 1012-1015.
(4) Zhang, H.; Hou, J.; Ou, R.; Hu, Y.; Wang, H.; Jiang, L. Periodic Oscillation of Ion Conduction of Nanofluidic Diodes Using a Chemical Oscillator. Nanoscale 2017, 9, 7297-7304.

(5) Wang, J.; Fang, R.; Hou, J.; Zhang, H.; Tian, Y.; Wang, H.; Jiang, L. Oscillatory Reaction Induced Periodic C-Quadruplex DNA Gating of Artificial Ion Channels. ACS Nano 2017, 11, 3022-3029.

(6) Zhao, C.; Lu, J.; Hou, J.; Li, X.; Wang, J.; Jiang, L.; Wang, H.; Zhang, H. Bioinspired Self-Gating Nanofluidic Devices for Autonomous and Periodic Ion Transport and Cargo Release. Adv. Funct. Mater. 2019, 29, 1806416.

(7) Zhou, H.-Y.; Han, Y.; Chen, C.-F. pH-Controlled Motions in Mechanically Interlocked Molecules. Mater. Chem. Front. 2020, 4, $12-28$.

(8) Rabai, G.; Orban, M.; Epstein, I. R. Systematic Design of Chemical Oscillators. 64. Design of pH-Regulated Oscillators. Acc. Chem. Res. 1990, 23, 258-263.

(9) Orbán, M.; Kurin-Csörgei, K.; Epstein, I. R. pH-Regulated Chemical Oscillators. Acc. Chem. Res. 2015, 48, 593-601.

(10) Orban, M.; Epstein, I. R. Systematic Design of Chemical Oscillators. 26. A New Halogen-Free Chemical Oscillator: The Reaction between Sulfide Ion and Hydrogen Peroxide in a CSTR. J. Am. Chem. Soc. 1985, 107, 2302-2305.

(11) Rushing, C. W.; Thompson, R. C.; Gao, Q. General Model for the Nonlinear $\mathrm{pH}$ Dynamics in the Oxidation of Sulfur(-II) Species. J. Phys. Chem. A 2000, 104, 11561-11565.

(12) Kurin-Csörgei, K.; Epstein, I. R.; Orbán, M. Systematic Design of Chemical Oscillators Using Complexation and Precipitation Equilibria. Nature 2005, 433, 139-142.

(13) Kurin-Csörgei, K.; Epstein, I. R.; Orbán, M. Periodic Pulses of Calcium Ions in a Chemical System. J. Phys. Chem. A 2006, 110, $7588-7592$

(14) Horváth, V.; Kurin-Csörgei, K.; Epstein, I. R.; Orbán, M. Oscillations in the Concentration of Fluoride Ions Induced by a $\mathrm{pH}$ Oscillator. J. Phys. Chem. A 2008, 112, 4271-4276.

(15) Horváth, V.; Kurin-Csörgei, K.; Epstein, I. R.; Orbán, M. Oscillatory Concentration Pulses of Some Divalent Metal Ions Induced by a Redox Oscillator. Phys. Chem. Chem. Phys. 2010, 12, $1248-1252$.

(16) Liedl, T.; Simmel, F. C. Switching the Conformation of a DNA Molecule with a Chemical Oscillator. Nano Lett. 2005, 5, 1894-1898.

(17) Liedl, T.; Olapinski, M.; Simmel, F. C. A Surface-Bound DNA Switch Driven by a Chemical Oscillator. Angew. Chem., Int. Ed. 2006, 45, 5007-5010.

(18) Liang, E.; Zhou, H.; Ding, X.; Zheng, Z.; Peng, Y. Fabrication of a Rhythmic Assembly System Based on Reversible Formation of Dynamic Covalent Bonds in a Chemical Oscillator. Chem. Commun. 2013, 49, 5384-5386.

(19) Qi, X.-J.; Lu, C.-H.; Liu, X.; Shimron, S.; Yang, H.-H.; Willner, I. Autonomous Control of Interfacial Electron Transfer and the Activation of DNA Machines by an Oscillatory pH System. Nano Lett. 2013, 13, 4920-4924.

(20) Lagzi, I.; Kowalczyk, B.; Wang, D.; Grzybowski, B. A Nanoparticle Oscillations and Fronts. Angew. Chem., Int. Ed. 2010, 49, 8616-8619.

(21) Nabika, H.; Oikawa, T.; Iwasaki, K.; Murakoshi, K.; Unoura, K. Dynamics of Gold Nanoparticle Assembly and Disassembly Induced by $\mathrm{pH}$ Oscillations. J. Phys. Chem. C 2012, 116, 6153-6158.

(22) Nabika, H.; Inumata, Y.; Oikawa, T.; Unoura, K. Effect of Gold Nanoparticle Dispersion Solution on the Oscillation Behavior of Nonlinear Chemical Reaction. Chem. Lett. 2012, 41, 1139-1141.

(23) Deng, F.; Feng, J.; Ding, T. Chemoplasmonic Oscillation: A Chemomechanical Energy Transducer. ACS Appl. Mater. Interfaces 2019, 11, 42580-42585.

(24) Varga, I.; Szalai, I.; Mészaros, R.; Gilányi, T. Pulsating pHResponsive Nanogels. J. Phys. Chem. B 2006, 110, 20297-20301.

(25) Wang, G.; Liu, Y.; Liu, Y.; Xia, N.; Zhou, W.; Gao, Q.; Liu, S. The Non-Equilibrium Self-Assembly of Amphiphilic Block Copolymers Driven by a PH Oscillator. Colloids Surf. A. Physicochem. Eng. Asp. 2017, 529, 808-814. 
(26) Xu, G.; Zhou, H.; Li, J.; Yin, L.; Zheng, Z.; Ding, X. Autonomous Fluorescence Regulation in Responsive Polymer Systems Driven by a Chemical Oscillating Reaction. Polym. Chem. 2016, 7, 3211-3215.

(27) Lagzi, I.; Wang, D.; Kowalczyk, B.; Grzybowski, B. A. Vesicleto-Micelle Oscillations and Spatial Patterns. Langmuir 2010, 26, 13770-13772.

(28) Holló, G.; Dúzs, B.; Szalai, I.; Lagzi, I. From Master-Slave to Peer-to-Peer Coupling in Chemical Reaction Networks. J. Phys. Chem. A 2017, 121, 3192-3198.

(29) Holló, G.; Lagzi, I. Autonomous Chemical Modulation and Unidirectional Coupling in Two Oscillatory Chemical Systems. J. Phys. Chem. A 2019, 123, 1498-1504.

(30) Srour, R. K.; McDonald, L. M. Determination of the Acidity Constants of Methyl Red and Phenol Red Indicators in Binary Methanol- and Ethanol-Water Mixtures. J. Chem. Eng. Data 2008, 53, 116-127.

(31) Alamgir, M.; Orban, M.; Epstein, I. R. Systematic Design of Chemical Oscillators. Part 16. Inorganic Bromate Oscillators. Bromate-Manganous-Reductant. J. Phys. Chem. 1983, 87, 3725-3728.

(32) Edblom, E. C.; Luo, Y.; Orban, M.; Kustin, K.; Epstein, I. R. Systematic Design of Chemical Oscillators. 45. Kinetics and Mechanism of the Oscillatory Bromate-Sulfite-Ferrocyanide Reaction. J. Phys. Chem. 1989, 93, 2722-2727.

(33) Rábai, G.; Hanazaki, I. pH Oscillations in the BromateSulfite-Marble Semibatch and Flow Systems. J. Phys. Chem. 1996, 100, 10615-10619.

(34) Hanazaki, I.; Rábai, G. Origin of Chemical Instability in the Bromate-Sulfite Flow System. J. Chem. Phys. 1996, 105, 9912-9920. (35) Szántó, T. G.; Rábai, G. pH Oscillations in the $\mathrm{BrO}_{3}{ }^{-}-\mathrm{SO}_{3}{ }^{2-}$ / $\mathrm{HSO}_{3}{ }^{-}$Reaction in a CSTR. J. Phys. Chem. A 2005, 109, 5398-5402. (36) Sato, N.; Hasegawa, H. H.; Kimura, R.; Mori, Y.; Okazaki, N. Analysis of the Bromate-Sulfite-Ferrocyanide $\mathrm{pH}$ Oscillator Using the Particle Filter: Toward the Automated Modeling of Complex Chemical Systems. J. Phys. Chem. A 2010, 114, 10090-10096.

(37) Poros, E.; Kurin-Csörgei, K.; Szalai, I.; Rábai, G.; Orbán, M. $\mathrm{pH}$-Oscillations in the Bromate-Sulfite Reaction in Semibatch and in Gel-Fed Batch Reactors. Chaos Interdiscip. J. Nonlinear Sci. 2015, 25, No. 064602. 